\title{
Postnatal Growth Patterns in a Chilean Cohort: The Role of SES and Family Environment
}

\author{
D. E. Kang Sim, ${ }^{1}$ M. Cappiello, ${ }^{1}$ M. Castillo, ${ }^{2}$ B. Lozoff, ${ }^{3}$ S. Martinez, ${ }^{1}$ \\ E. Blanco, ${ }^{1}$ and S. Gahagan ${ }^{1}$ \\ ${ }^{1}$ Division of Child Development and Community Health, University of California, San Diego, 9500 Gilman Drive No. 0927, La Jolla, \\ CA 92093-0927, USA \\ ${ }^{2}$ Institute of Nutrition and Food Technology (INTA), University of Chile, El Líbano 5524, Santiago, Chile \\ ${ }^{3}$ Center for Human Growth and Development, University of Michigan, Ann Arbor 300 North Ingalls, 10th Floor, Ann Arbor, \\ MI 48109-5406, USA
}

Correspondence should be addressed to S. Gahagan, sgahagan@ucsd.edu

Received 15 December 2011; Revised 18 February 2012; Accepted 4 March 2012

Academic Editor: Tessa J. Roseboom

Copyright $\odot 2012$ D. E. Kang Sim et al. This is an open access article distributed under the Creative Commons Attribution License, which permits unrestricted use, distribution, and reproduction in any medium, provided the original work is properly cited.

Objective. This study examined how family environmental characteristics served as mediators in the relationship between socioeconomic conditions and infant growth in a cohort of Chilean infants. Methods. We studied 999 infants, born between 1991 and 1996, from a longitudinal cohort which began as an iron deficiency anemia preventive trial. SES (Graffar Index), the Life Experiences Survey, and the Home Observation for Measurement of the Environment (HOME) were assessed in infancy. Using path analysis, we assessed the relationships between the social factors, home environment, and infant growth. Results. During the first year, weight and length gain averaged 540 grams/month and $6.5 \mathrm{~cm} / \mathrm{month}$, respectively. In the path analysis model for weight gain, higher SES and a better physical environment were positively related to higher maternal warmth, which in turn was associated with higher average weight gain. Higher SES was directly related to higher average length gain. Conclusions. In our cohort, a direct relationship between SES and length gain developed during infancy. Higher SES was indirectly related to infant weight gain through the home environment and maternal warmth. As the fastest growing infants are at risk for later obesity, new strategies are needed to encourage optimal rather than maximal growth.

\section{Introduction}

Infant growth can have important long-term health and developmental consequences. In the case of poor weight gain, cognitive development can be impaired $[1,2]$. When infancy weight gain is rapid, risk for obesity and related conditions increases [3-8]. Whether or not infant weight gain relates to socioeconomic status depends on context. Infants gain less weight in resource poor settings in underdeveloped countries $[9,10]$. In developed countries, lower socioeconomic status (SES) can relate to risk for poor infant growth through several possible mechanisms including higher rates of postpartum depression or family size [11-14]. On the other hand, a recent study in a developed country showed higher infant weight gain in lower SES individuals, largely explained by lower breast feeding rates [15]. Lastly, in some settings SES has not been found to influence infant ponderal growth [16]. Thus, it is important to understand the relationship of SES to infancy weight gain in a variety of contexts and identify factors that might mediate this relationship.

When the availability of breast milk or formula and weaning foods is adequate, the relationship between SES and infant weight gain might be explained by stressful circumstances and characteristics of the home environment and the parent-infant relationship. Low-SES families are more likely to experience uncontrollable life events and may have less healthy home environments for children [17], including lower quality stimulation available in the home for children [18]. Previous research has shown that negative circumstances associated with poverty and distress among parents can compromise parents' abilities to provide sensitive, involved, and consistent parenting [19-21]. Parenting style and infant 
growth have been most often explored in the context of failure to thrive, with harsh and neglectful parenting associated with poor infant growth [22].

Understanding linear growth as it relates to SES is also important, as height can be a marker of health risk. At the population level, adult height is socially determined [23, 24]. Height reflects prenatal and postnatal environments superimposed on genetic potential [25]. In addition, adult height shows an inverse association with cardiovascular [26, 27] and cardiorespiratory [27] disease, some cancers [28], and type 2 diabetes [29]. Socioeconomic gradients in height are also present in childhood and have been noted at the time of birth in representative samples [30]. A recent study in the UK that found differences in birth length based on SES did not show further differences in growth during infancy [30]. In contexts where infant nutrition is adequate, questions remain about whether or not social factors relate to linear growth during the first year.

In order to answer the question of whether or not postnatal growth was related to SES and how family environment might mediate these relationships, we used data on birth weight and length and 12-month weight, length, SES and variables from the Home Observation for Measurement of the Environment (HOME) [31] from a large, longitudinal cohort of Chilean infants. This allowed us to establish direct and indirect associations between SES, family factors and infant growth.

\section{Methods}

This study is a secondary data analysis to identify the relationship of socioeconomic status (SES) with ponderal (weight) and linear (length) growth and to identify family factors that mediate this relationship, in a cohort of Chilean infants during the first year of life. The infants were enrolled in a randomized controlled trial of iron to prevent iron deficiency anemia. The parent study is described first, followed by methods for the secondary data analysis.

\section{Original Study}

From 1991 through 1996, we recruited healthy low- to middle-income, urban Chilean infants with birth weights of $\geq 3 \mathrm{~kg}$ for a double-blind, randomized, controlled trial of iron supplementation between 6 and 12 months of age [32]. At the time in Chile, infant health was generally excellent. In fact, parasitic infections and generalized undernutrition were virtually absent. However, dietary iron deficiency was common, and iron supplementation during infancy was not routine. In the trial, infants were randomized to iron supplementation or usual nutrition at 6 months. All but 8 of the cohort were initially breast fed, but approximately one third were supplemented in the first 6 weeks with formula made from powdered full fat cow's milk. The cohort continues to be followed with waves of data collection at $5 \mathrm{y}, 10 \mathrm{y}$, and $16 \mathrm{y}$. The protocols for the original infant study and followup studies have been approved annually by the Institutional
Review Boards of the Universities of Michigan and Chile, and the University of California, San Diego.

\section{Secondary Analysis of the Influence of SES on Growth and Mediating Factors}

Of the 1657 infants who completed the preventive trial, 999 had complete data on all variables for this analysis. Those without complete data did not differ significantly from those included in this analysis by birth weight or length, sex, SES, or family factors.

4.1. Outcome Variable. Unclothed infant weight, using an electronic scale (to the nearest $0.01 \mathrm{~kg}$ ), and length, on a recumbent length board (to the nearest $0.1 \mathrm{~cm}$ ), were measured monthly in the first year by trained nurses [33]. Infant weight gain over the first year (grams per month) was calculat-ed as: (weight $(\mathrm{kg})$ at 1 year - birth weight $(\mathrm{kg})) /($ age (days) $* 30.44$ days/month). Infant length over the first year (grams per month) was calculated as (length $(\mathrm{cm})$ at 1 year birth length $(\mathrm{cm})) /($ age (days) $* 30.44$ days/month).

4.2. Variable of Interest. SES was measured using a modified Graffar index, which included 10 items concerning family size and structure, father presence, educational level of head of household, home ownership, and ownership of appliances [34]. For this analysis, the scale was dichotomized based on the median score of 27 (range of 16 to 47 ), with " 0 " referring to low SES and " 1 " referring to middle SES.

4.3. Social Factors. Mothers provided the following information at the 1-year assessment. Life stress was assessed using the Life Experiences Survey [35, 36] which included 22 items such as unstable employment of the head of household, serious family conflict, and serious illness of a relative, for a possible score of 0-22 (Cronbach alpha $=0.67)$. Maternal depression risk was assessed using the Center for Epidemiological Studies Depression Scale (CES-D) [37] scale; a score of 16 or greater indicates risk for depression. Adult-tochild ratio [14] served as a marker of family composition. This ratio was computed as the number of income-earning adults/number of children under age 15 . This variable was trichotomized, with " 0 " referring to one adult to one child (ratio of 1), "1" referring to more adults than children (ratio greater than 1 ), and " -1 " referring to more children than adults (ratio less than 1 ).

4.4. Other Mediating Factors. Mediating factors included variables representing the infant's family and home environments. The Home Observation for Measurement of the Environment scale (HOME), measured by direct observation, was used to evaluate the quality of the home environment for nurturing (Cronbach alpha $=0.80$ ) [38]. In the US, 6 HOME subscales are used. In this Chilean sample, we identified 5 factors using exploratory factor analysis: "maternal warmth and emotional support," "sibling participation," "physical environment," "father-infant interaction," and "cognitive stimulation." Table 1 displays Eigen values and items, with 
TABLE 1: Exploratory factor structures and item statistics: maternal warmth, sibling participation, and physical environment ${ }^{\mathrm{a}}$.

\begin{tabular}{|c|c|c|c|}
\hline \multirow{2}{*}{ Item content } & \multicolumn{3}{|c|}{ Correlations } \\
\hline & Maternal warmth & $\begin{array}{c}\text { Sibling } \\
\text { participation }\end{array}$ & $\begin{array}{c}\text { Physical } \\
\text { environment }\end{array}$ \\
\hline Mother's voice conveys positive feelings toward child & 45 & & \\
\hline Mother caresses or kisses child at least once & 45 & & \\
\hline Mother spontaneously praises child at least twice & 42 & & \\
\hline Child's play environment is safe & & & 74 \\
\hline $\begin{array}{l}\text { When the child gets close to the mother, she welcomes, looks at, listens to, } \\
\text { and is affectionate towards him/her }\end{array}$ & 49 & & \\
\hline The child is spontaneously taken up in the arms of his/her older siblings & & 76 & \\
\hline $\begin{array}{l}\text { The child is spontaneously caressed, kissed, or tickled by older siblings at } \\
\text { least } 5 \text { minutes of everyday }\end{array}$ & & 93 & \\
\hline $\begin{array}{l}\text { The child is spontaneously conversed to in a directed and appropriate } \\
\text { manner by older siblings }\end{array}$ & & 89 & \\
\hline $\begin{array}{l}\text { The child is spontaneously incorporated into family activities by older } \\
\text { siblings }\end{array}$ & & 84 & \\
\hline $\begin{array}{l}\text { There are other people who are consistently important in the } \\
\text { encouragement and care of the child }\end{array}$ & & 39 & \\
\hline The interior of the house has sufficient light and ventilation & & & 46 \\
\hline The bedroom in the house is reasonably clean and orderly & & & 55 \\
\hline $\begin{array}{l}\text { With respect to the spare available space, there is sufficient room for the } \\
\text { child to explore and crawl without danger }\end{array}$ & & & 74 \\
\hline Eigen values & 2.58 & 3.26 & 2.38 \\
\hline
\end{tabular}

${ }^{a}$ Values are multiplied by 100 and rounded to the nearest integer. Only the factor items with correlations $\geq 35$ are displayed.

factor-item correlations of 0.35 or higher. "Father-infant interaction" and "cognitive stimulation" were not significantly associated with infant weight gain and were excluded from the final analysis in favor of a more parsimonious model. We tested additional covariates that might partially explain the relationship between SES and growth in weight and length. As the cohort was part of an IDA preventive trial, we tested whether IDA at one-year or random assignment to iron influenced the relationship between SES and growth in the first year. We tested the effect of gestational age and number of children on weight and length gain. Gestational age (in weeks) was assessed by the date of the last menstrual period; number of children was self-reported by the mother. Lastly, we tested whether 2 separate measures of breastfeeding were related to infancy weight and length gain: bottle supplementation at 6 weeks and still breastfeeding at 6 months. Both measures were self-reported by mothers during the infancy data collection period.

\section{Statistical Analysis}

Statistical analyses were conducted using SAS (9.2; Cary, NC) and SPSS (17; Chicago, IL). Descriptive statistics included means and frequencies (Table 2). We compared our sample (sample with complete data) to those excluded due to missing data, with $t$-test and chi-square analyses. We developed a path analysis model to assess the relationships between SES and correlated variables, adult-to-child ratio, and life stress, and infant weight gain and length gain, mediated by the family and home environment (sibling participation in child care, the physical home environment related to nurturing, and maternal warmth). Path analyses were performed using SAS PROC CALIS. Standardized regression coefficients and $t$-statistics were used to describe the final model; $t$-values $>1.96$ were statistically significant. Model fit was tested using the chi-square statistic $\left(\chi^{2} ; P>\right.$ $0.05)$. Goodness-of-fit indices included the root mean square error of approximation (RMSEA $<0.06$ ), comparative fit index $(\mathrm{CFI}>0.95)$, and standardized root mean square residual $(\mathrm{SRMR}<0.03)$.

\section{Results}

Descriptive statistics are shown in Table 2. Infants were $53 \%$ male, averaged $3.5 \mathrm{~kg}$ and $50.6 \mathrm{~cm}$ at birth, gained on average 539 grams/month in the first year, and were at the 49th percentile for weight-for-age at 1 year. Infants' mean linear growth in the first year was $6.5 \mathrm{~cm} / \mathrm{month}$, and mean length-for-age percentile at 1 year was 48 th percentile. Only 3 percent of the 1 year-olds had heights less than the 5 th percentile. Most infants (59\%) lived in households containing more children than adults. The life stress scores ranged from 0 to 14 and averaged 4.8 (2.7). Table 3 shows additional descriptive information on the social variables, stratified by SES. Participants in the middle SES group, compared to those with low SES, had better optimal nurturing environment with higher maternal warmth and 
TABle 2: Descriptive statistics of Chilean infants $(n=999)^{1}$.

\begin{tabular}{|c|c|}
\hline Birth weight $(\mathrm{kg})^{2}$ & $3.5(0.4)$ \\
\hline Birth length $(\mathrm{cm})^{2}$ & $50.6(1.7)$ \\
\hline Gestational age & $39.4(1.0)$ \\
\hline Age at infancy evaluation & $11.5(0.4)$ \\
\hline Weight-for-age percentile at 1 year ${ }^{2}$ & $48.7(27.1)$ \\
\hline Average weight gain (grams/month) & $539.2(84.2)$ \\
\hline Length-for-age percentile at 1 year ${ }^{2}$ & $47.8(25.8)$ \\
\hline Average length gain (cm/month) & $6.5(0.3)$ \\
\hline Bottle supplementation at 6 weeks & 25.0 \\
\hline Still breastfeeding at 6 months & 49.3 \\
\hline Number of siblings & $2.1(1.1)$ \\
\hline Iron deficiency anemia in infancy & 15.2 \\
\hline Iron supplemented & 78.5 \\
\hline Maternal risk for depression & 45.7 \\
\hline Life stress & $4.8(2.7)$ \\
\hline Physical environment $^{3}$ & $2.8(1.3)$ \\
\hline Maternal warmth ${ }^{3}$ & $3.4(0.8)$ \\
\hline Sibling participation ${ }^{3}$ & $3.9(1.7)$ \\
\hline \multicolumn{2}{|l|}{ Gender $^{2}$} \\
\hline Male & 52.6 \\
\hline Female & 47.4 \\
\hline \multicolumn{2}{|l|}{ SES } \\
\hline Middle SES & 52.7 \\
\hline Low SES & 47.3 \\
\hline \multicolumn{2}{|l|}{ Adult-to-child ratio } \\
\hline One-to-one ratio & 26.4 \\
\hline More adults & 15.1 \\
\hline More children & 58.5 \\
\hline
\end{tabular}

${ }^{1}$ Values are mean (SD) or \%.

${ }^{2}$ Variable not included in the final model.

${ }^{3}$ Derived from HOME.

TABLE 3: Social factors by SES category.

\begin{tabular}{lcc}
\hline & Middle SES & Low SES \\
\hline Maternal warmth* & $3.6(0.8)$ & $3.4(0.8)$ \\
Sibling participation* & $3.7(1.7)$ & $4.0(1.6)$ \\
Physical environment* & $3.2(1.1)$ & $2.4(1.4)$ \\
More adults compared to children* & $19.0 \%$ & $10.8 \%$ \\
Stressful events* & $4.5(2.6)$ & $5.0(2.6)$ \\
\hline$* P<0.05$ & &
\end{tabular}

physical home environment, lower sibling participation in infant care, and fewer stressful events.

Figure 1 shows the standardized path coefficients and respective $t$-values for the tested model. All paths shown are statistically significant associations. Fit indices indicated a good model fit $($ RMSEA $=0.03, \mathrm{CFI}=0.97$, and SRMR $=$ $0.02)$. SES was significantly correlated with adult-to-child ratio and life stress. Adult-to-child ratio was negatively associated with sibling participation $(B=-0.45, P<0.05)$, which negatively related to weight gain $(B=-0.14, P<$ $0.05)$. SES $(B=0.28, P<0.05)$ and adult-to-child ratio $(B=0.10, P<0.05)$ were related to a more positive physical environment for nurturing, and higher life stress was related to a less positive physical environment $(B=-0.10, P<$ $0.05)$. The physical environment indirectly related to weight gain through greater maternal warmth $(B=0.07, P<0.05)$. SES was indirectly related to infant weight gain through a more positive physical environment $(B=0.28, P<0.05)$ and greater maternal warmth $(B=0.08, P<0.05)$.

We now examine the strength of the associations. Of the social factors, the strongest relationships were those between adult-to-child ratio and lower sibling participation in childcare and between SES and the physical environment for nurturing. The relationships between life stress and physical environment and adult-to-child ratio and physical environment were less robust, but significant. No direct associations between SES, adult-to-child ratio, and life stress and infant growth were found. We also tested potential covariates, including iron deficiency anemia, iron assignment, depression, gestational age, number of children, and bottle supplementation of breast feeding at 6 weeks and continued breast feeding at 6 months. With the exception of number of children, which had a direct inverse relationship with weight gain $(B=-0.08, P<0.05)$, these factors did not significantly contribute to the model and were omitted for parsimony. Sibling participation, maternal warmth, and number of children accounted for $3 \%$ of the variance in infant weight gain.

In examining infancy length gain (Figure 2), we found pathways identical to those associated with weight gain, with the exception that there was no relationship between maternal warmth and length gain. Additionally, SES was directly related to infancy length gain, rather than indirectly as was found for weight gain $(B=0.06, P=0.05)$. This relationship was marginally significant, and the strength of the association was modest. As in the weight gain model, iron deficiency anemia, iron assignment, depression, gestational age, and bottle supplementation of breast feeding at 6 weeks and continued breast feeding at 6 month did not significantly contribute to the model and were omitted for parsimony. Number of children was directly and inversely related to infancy length gain $(B=-0.07, P<0.05)$. Sibling participation, number of children, and SES accounted for $1 \%$ of the variance in infant length gain.

\section{Discussion}

This study examined the relationship between SES and family factors and postnatal growth. Results showed that infant linear growth was directly related to SES, while ponderal growth was indirectly related to SES, mediated by the physical environment for nurturing and maternal warmth. In fact, the physical environment was a pivotal-mediating factor that linked the social variables to infant weight gain. This finding suggests that less strained financial circumstances provided a more supportive home environment. This, in turn, related to higher infant weight gain indirectly through maternal warmth.

Prior research has shown direct relationships between SES and birth length as well as SES and adult height 


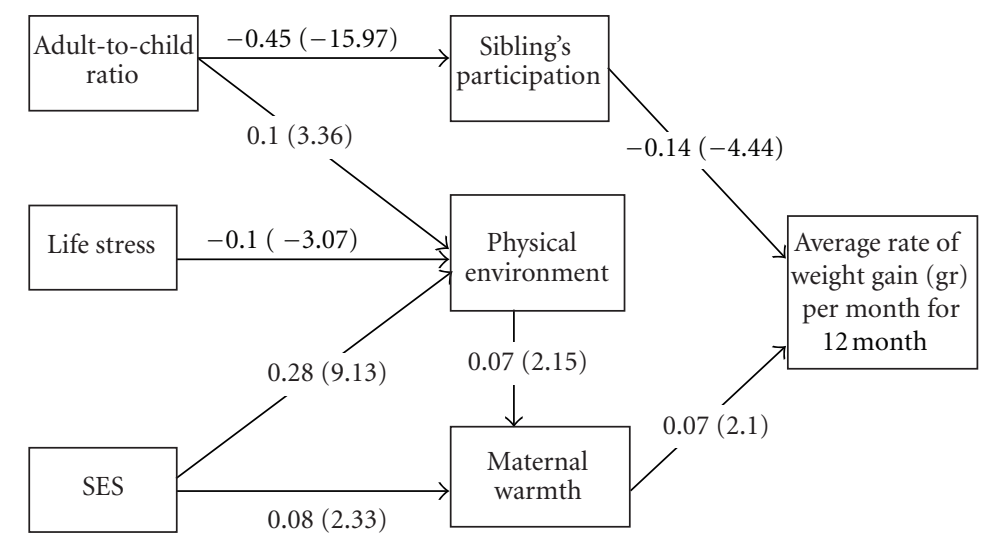

FIGURE 1: Standardized path coefficients ( $t$-values) for a path model between SES and infant weight gain, mediated by home environment in 1-year-old Chilean infants $(\mathrm{CFI}=0.97, \mathrm{SRMR}=0.02$, RMSEA $=0.03)$. All paths are statistically significant $(P<0.05)$. SES significantly correlated with adult-to-child ratio and life stress. Model adjusted for direct relationship between number of children and average weight gain $(P<0.05)$.

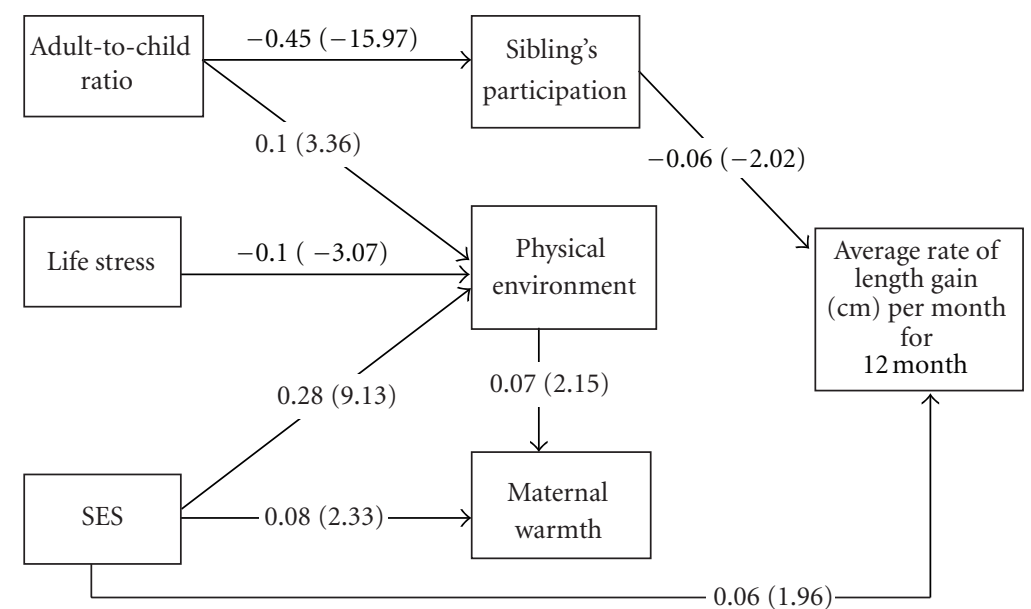

FIGURE 2: Standardized path coefficients ( $t$-values) for a path model between SES and infant length gain, mediated by home environment in 1-year-old Chilean infants $(\mathrm{CFI}=0.98, \mathrm{SRMR}=0.02$, RMSEA $=0.03)$. All paths are statistically significant $(P<0.05)$. SES significantly correlated with adult-to-child ratio and life stress.

$[23,24,30]$. However, in previous work, the infant SESlength relationship has been largely explained by the association already existing at birth [39]. This was not the case in our study, perhaps because infants weighing less than $3 \mathrm{~kg}$ at birth were excluded, resulting in less variation in birth length than would be found in a representative cohort. The relationship between SES and postnatal length gain was independent of birth length in our sample. This gradient was not mediated by the family or nutritional factors examined, suggesting that other unmeasured characteristics related to SES were responsible. It is highly unlikely that macronutrient factors were responsible for this finding, as none of the infants exhibited poor growth, almost all were initially breast fed, and supplemental milk was freely available from the Chilean National Health Service. Other potential explanations include micronutrient deficiencies or stressful circumstances affecting the hypothalamic-pituitaryadrenal axis.
In the context of this study of low- to middle-income, urban Chilean families, SES was related to infant weight gain. It is important to note that substantial public health programs in Chile led to a decline in infant mortality from $136.2 / 1000$ live births in 1950 to $8.9 / 1000$ live births in 2000. During this period, infant malnutrition was virtually eradicated through a supplemental milk program and a national breast feeding campaign that was highly successful [40]. In our study, the relationship between SES and infant growth was explained by family factors including family composition, the physical environment, and maternal warmth. All of the factors associated with more rapid weight gain are related to good nurturing. We also tested the role of breast feeding exclusivity and duration on these associations and found no effect. We suspect that the homogeneity of our sample in terms of high breast feeding rates minimized the effect of nutritional factors in our study. Another nutritional factor that could play a role is the timing of introduction of 
complementary foods, but we do not have data on this feeding practice. A recent study of infant growth in a multiethnic cohort in Amsterdam found higher growth rates in ethnic minority families that could not be entirely explained by different feeding practices [41]. Our study adds to the existing literature by supporting the role of psychosocial factors in infant growth. While there is a large literaturerelating psychosocial factors to failure to thrive [22, 42], these characteristics are not always considered in infant growth research when failure to thrive is not the focus.

Our findings lead to a difficult question, how can optimal infancy growth be promoted in an era when failure to thrive is rare and risk for obesity is high. Historically, malnutrition presented serious risk for infants in Chile and had only recently been eradicated at the time our cohort participants were infants [40]. Currently in Chile, less than $2.9 \%$ of children under 6 years old are malnourished, and only $0.3 \%$ have moderate to severe malnutrition [40]. On the other hand, 16-20 years ago when our cohort participants were infants, the obesity epidemic was beginning in Chile but was not known or evident to families or even to health providers. In 2005, preschool age Chilean children had high obesity rates: $6 \%$ of 2 -year olds, $11 \%$ of 3 -year olds, and $14 \%$ of 4 -year olds were obese. By young adulthood (17-24 years), the overweight and obesity prevalence was $24 \%$ in men and $28 \%$ in women [43]. In our study, the families with the most resources had infants with more rapid length and weight gain. We now know that rapid weight gain in infancy creates risk for later obesity $[44,45]$, which creates a conundrum for all involved. It appears that what would be considered optimal care is associated with increased risk for later obesity. Therefore, the fattest baby can no longer be viewed as the healthiest baby. While significant progress has been made in promoting breast feeding and encouraging families to delay supplemental bottles and complementary foods in Chile [40] and in many other settings $[46,47]$, it will be important to change perceptions of families about what a healthy baby looks like and what constitutes optimal growth. As these perceptions are highly linked with cultural norms, this will take a concerted effort on many fronts.

Some of this study's particular strengths are worth noting. This large cohort of infants was assessed at a university nutrition research center where the infants had detailed anthropometric measurement every month in the first year of life. In addition, data on SES, family factors and infant feeding were prospectively collected. Furthermore, most studies of SES and infant growth have been carried out in developed countries and may not relate to infants in other settings. Our study also has important limitations. The cross-sectional path analysis model cannot establish temporal precedence nor infer causality. It therefore must be considered to be hypothesis generating. Furthermore, findings about the SES infant-growth relationship from one context may not apply in other settings. Therefore, it may not be possible to generalize these findings to other cultures, rural settings, higher SES groups, or to other countries. Regarding generalizing to Chile in more recent years, however, it is important to note that infant growth rates in a more contemporary Chilean census, born between
2002 and 2004, are similar to those of our study for infants who weighted $3 \mathrm{~kg}$ or greater at birth [48].

\section{Conclusion}

In this developing country setting of rapid economic and nutritional transition, better circumstances related to higher infant growth. Prior to the onset of the global obesity epidemic, higher infant growth would have always been a sign of good parenting and prosperity and would have portended a survival advantage for the infant. In the current era, infants who are growing the fastest are at risk for developing obesity [45]. These findings emphasize the need for better understanding of explanatory factors related to infant growth. Future research should include longitudinal studies in a variety of settings that could identify possible causal elements including biological factors, such as genetics and the effects of the intrauterine environment, and environmental factors such as nutrition and the psychosocial environment.

\section{Conflict of Interests}

The authors declare that there is no conflict of interests.

\section{Acknowledgments}

The authors would like to express their gratitude to the participants and their families for their ongoing participation. This study was supported by grants from the National Institutes of Health, Heart, Lung, and Blood Institute (HL088530, PI: Gahagan) and the National Institute of Child Health and Human Development (HD14122 and HD33487, PI: Lozoff). The content is solely the responsibility of the authors and does not necessarily represent the official views of the National Institutes of Health.

\section{References}

[1] S. S. Corbett and R. F. Drewett, "To what extent is failure to thrive in infancy associated with poorer cognitive development? A review and meta-analysis," Journal of Child Psychology and Psychiatry and Allied Disciplines, vol. 45, no. 3, pp. 641654, 2004.

[2] A. M. Emond, P. S. Blair, P. M. Emmett, and R. F. Drewett, "Weight faltering in infancy and IQ levels at 8 years in the Avon Longitudinal Study of Parents and Children," Pediatrics, vol. 120, no. 4, pp. e1051-e1058, 2007.

[3] M. B. Belfort, S. L. Rifas-Shiman, J. Rich-Edwards, K. P. Kleinman, and M. W. Gillman, "Size at birth, infant growth, and blood pressure at three years of age," Journal of Pediatrics, vol. 151, no. 6, pp. 670-674, 2007.

[4] J. Botton, B. Heude, J. Maccario, P. Ducimetiere, and M. A. Charles, "Postnatal weight and height growth velocities at different ages between birth and $5 \mathrm{y}$ and body composition in adolescent boys and girls," American Journal of Clinical Nutrition, vol. 87, no. 6, pp. 1760-1768, 2008.

[5] S. Chomtho, J. C. K. Wells, J. E. Williams, P. S. W. Davies, A. Lucas, and M. S. Fewtrell, "Infant growth and later body composition: evidence from the 4-component model," American 
Journal of Clinical Nutrition, vol. 87, no. 6, pp. 1776-1784, 2008.

[6] U. Ekelund, K. Ong, Y. Linné et al., "Upward weight percentile crossing in infancy and early childhood independently predicts fat mass in young adults: the Stockholm Weight Development Study (SWEDES)," American Journal of Clinical Nutrition, vol. 83, no. 2, pp. 324-330, 2006.

[7] Y. Ben-Shlomo, A. McCarthy, R. Hughes, K. Tilling, D. Davies, and G. D. Smith, "Immediate postnatal growth is associated with blood pressure in young adulthood: the Barry Caerphilly Growth Study," Hypertension, vol. 52, no. 4, pp. 638-644, 2008.

[8] A. Singhal, T. J. Cole, M. Fewtrell et al., "Promotion of faster weight gain in infants born small for gestational age: is there an adverse effect on later blood pressure?" Circulation, vol. 115, no. 2, pp. 213-220, 2007.

[9] M. A. Subramanyam, I. Kawachi, L. F. Berkman, and S. V. Subramanian, "Socioeconomic inequalities in childhood undernutrition in India: analyzing trends between 1992 and 2005," PLoS One, vol. 5, no. 6, Article ID e11392, 2010.

[10] A. Ashworth, S. S. Morris, and P. I. C. Lira, "Postnatal growth patterns of full-term low birth weight infants in northeast Brazil are related to socioeconomic status," Journal of Nutrition, vol. 127, no. 10, pp. 1950-1956, 1997.

[11] L. S. Segre, M. W. O’Hara, S. Arndt, and S. Stuart, “The prevalence of postpartum depression: the relative significance of three social status indices," Social Psychiatry and Psychiatric Epidemiology, vol. 42, no. 4, pp. 316-321, 2007.

[12] L. M. O’Brien, E. G. Heycock, M. Hanna, P. W. Jones, and J. L. Cox, "Postnatal depression and faltering growth: a community study," Pediatrics I, vol. 113, no. 5, pp. 1242-1247, 2004.

[13] E. H. Hagen, H. C. Barrett, and M. E. Price, "Do human parents face a quantity-quality tradeoff?: evidence from a shuar community," American Journal of Physical Anthropology, vol. 130, no. 3, pp. 405-418, 2006.

[14] W. Fowler, "How adult/child ratios influence infant development," Interchange, vol. 6, no. 1, pp. 17-31, 1975.

[15] L. P. M. M. Wijlaars, L. Johnson, C. H. M. Van Jaarsveld, and J. Wardle, "Socioeconomic status and weight gain in early infancy," International Journal of Obesity, vol. 35, no. 7, pp. 963-970, 2011.

[16] A. Emond, R. Drewett, P. Blair, and P. Emmett, "Postnatal factors associated with failure to thrive in term infants in the Avon Longitudinal Study of Parents and Children," Archives of Disease in Childhood, vol. 92, no. 2, pp. 115-119, 2007.

[17] P. H. Casey, B. Wortham, and R. Bradley, "Social and nonsocial home environments of infants with nonorganic failure-tothrive," Pediatrics, vol. 73, no. 3, pp. 348-353, 1984.

[18] R. H. Bradley and B. M. Caldwell, "The HOME Inventory and family demographics," Developmental Psychology, vol. 20, no. 2, pp. 315-320, 1984.

[19] V. C. McLoyd, N. L. Aikens, and L. M. Burton, "Childhood poverty, policy, and practice," in Handbook of Child Psychology, John Wiley \& Sons, New York, NY, USA, 2007.

[20] C. S. Tamis-LeMonda and R. Kahana-Kalman, "Mothers' views at the transition to a new baby: variation across ethnic groups," Parenting, vol. 9, no. 1-2, pp. 36-55, 2009.

[21] J. D. Shannon, C. S. Tamis-LeMonda, and A. Margolin, "Father involvement in infancy: Influences of past and current relationships," Infancy, vol. 8, no. 1, pp. 21-41, 2005.

[22] M. M. Black, J. J. Hutcheson, H. Dubowitz, and J. BerensonHoward, "Parenting style and developmental status among children with nonorganic failure to thrive," Journal of Pediatric Psychology, vol. 19, no. 6, pp. 689-707, 1994.
[23] M. G. Marmot, G. D. Smith, S. Stansfeld et al., "Health inequalities among British civil servants: the Whitehall II study," The Lancet, vol. 337, no. 8754, pp. 1387-1393, 1991.

[24] D. A. Leon, G. D. Smith, M. Shipley, and D. Strachan, "Adult height and mortality in London: early life, socioeconomic confounding, or shrinkage?" Journal of Epidemiology and Community Health, vol. 49, no. 1, pp. 5-9, 1995.

[25] N. Cameron, "Human growth and development," in Human Growth and Development, N. Cameron, Ed., Academic Press, London, UK, 2006.

[26] P. R. Hebert, J. W. Rich-Edwards, J. E. Manson et al., "Height and incidence of cardiovascular disease in male physicians," Circulation I, vol. 88, no. 4, pp. 1437-1443, 1993.

[27] G. D. Smith, C. Hart, M. Upton et al., "Height and risk of death among men and women: aetiological implications of associations with cardiorespiratory disease and cancer mortality," Journal of Epidemiology and Community Health, vol. 54, no. 2, pp. 97-103, 2000.

[28] G. Davey Smith, M. Shipley, and D. A. Leon, "Height and mortality from cancer among men: prospective observational study," British Medical Journal, vol. 317, no. 7169, pp. 13511352, 1998.

[29] P. Jousilahti, J. Tuomilehto, E. Vartiainen, J. Eriksson, and P. Puska, "Relation of adult height to cause-specific and total mortality: a prospective follow-up study of 3199 middle-aged men and women in Finland," American Journal of Epidemiology, vol. 151, no. 11, pp. 1112-1120, 2000.

[30] E. Whitley, R. M. Martin, G. D. Smith, J. M. Holly, and D. Gunnell, "The association of childhood height, leg length and other measures of skeletal growth with adult cardiovascular disease: the Boyd-Orr cohort," Journal of Epidemiology and Community Health, vol. 66, no. 1, pp. 18-23, 2012.

[31] R. H. Bradley, D. J. Mundfrom, L. Whiteside, P. H. Casey, and K. Barrett, "A factor analytic study of the infant-toddler and early childhood versions of the HOME Inventory administered to white, black, and Hispanic American parents of children born preterm," Child Development, vol. 65, no. 3, pp. 880-888, 1994.

[32] B. Lozoff, I. de Andraca, M. Castillo, J. B. Smith, T. Walter, and P. Pino, "Behavioral and developmental effects of preventing iron-deficiency anemia in healthy full-term infants," Pediatrics, vol. 112, no. 4, pp. 846-854, 2003.

[33] T. G. Lohman, A. F. Roche, and R. Martorell, Anthropometric Standardization Reference Manual, Human Kinetics Books, Champaign, Ill, USA, 1988.

[34] M. Graffar, "Une methode de classification sociales d'echantillons de population," Courrier, vol. 6, pp. 445-459, 1956.

[35] K. A. Crnic, M. T. Greenberg, A. S. Ragozin, N. M. Robinson, and R. B. Basham, "Effects of stress and social support on mothers and premature and full-term infants," Child Development, vol. 54, no. 1, pp. 209-217, 1983.

[36] I. G. Sarason, J. H. Johnson, and J. M. Siegel, "Assessing the impact of life changes: development of the life experiences survey," Journal of Consulting and Clinical Psychology, vol. 46, no. 5, pp. 932-946, 1978.

[37] L. S. Radloff, “The CES-D scale: a self-report depression scale for research in the general population," Applied Psychological Measurement, vol. 1, no. 3, pp. 385-401, 1977.

[38] V. Totsika and K. Sylva, "The home observation for measurement of the environment revisited," Child and Adolescent Mental Health, vol. 9, no. 1, pp. 25-35, 2004.

[39] M. L. A. de Hoog, M. van Eijsden, K. Stronks, R. J. B. J. Gemke, and T. G. M. Vrijkotte, "Overweight at age two years in a multiethnic cohort (ABCD study): the role of prenatal factors, birth 
outcomes and postnatal factors," BMC Public Health, vol. 11, article 611, 2011.

[40] J. Jiménez and M. I. Romero, "Reducing infant mortality in Chile: success in two phases," Health Affairs, vol. 26, no. 2, pp. 458-465, 2007.

[41] M. L. de Hoog, M. van Elijsden, K. Stronks, R. J. Gemke, and T. G. Vrijkotte, "The role of infant feeding practices in the explanation for ethnic differences in infant growth: the Amsterdam Born Children and their Development study," British Journal of Nutrition, vol. 106, no. 10, pp. 1592-1601, 2011.

[42] C. M. Wright, K. N. Parkinson, and R. F. Drewett, "The influence of maternal socioeconomic and emotional factors on infant weight gain and weight faltering (failure to thrive): data from a prospective birth cohort," Archives of Disease in Childhood, vol. 91, no. 4, pp. 312-317, 2006.

[43] F. Vio, C. Albala, and J. Kain, "Nutrition transition in Chile revisited: mid-term evaluation of obesity goals for the period 2000-2010," Public Health Nutrition, vol. 11, no. 4, pp. 405412, 2008.

[44] J. Baird, D. Fisher, P. Lucas, J. Kleijnen, H. Roberts, and C. Law, "Being big or growing fast: systematic review of size and growth in infancy and later obesity," British Medical Journal, vol. 331, no. 7522, pp. 929-931, 2005.

[45] A. Larnkjær, L. Schack-Nielsen, C. Mølgaard, H. K. Ingstrup, J. J. Holst, and K. F. Michaelsen, "Effect of growth in infancy on body composition, insulin resistance, and concentration of appetite hormones in adolescence," American Journal of Clinical Nutrition, vol. 91, no. 6, pp. 1675-1683, 2010.

[46] J. Von Rosen-Von Hoewel, K. Laitinen, E. Martin-Bautista et al., "Obesity related programming statements in materials on infant feeding aimed at parents in five European countries," Advances in Experimental Medicine and Biology, vol. 646, pp. 175-181, 2009.

[47] A. Imdad, M. Y. Yakoob, and Z. A. Bhutta, "Effect of breastfeeding promotion interventions on breastfeeding rates, with special focus on developing countries," BMC Public Health, vol. 11, no. 3, article S24, 2011.

[48] J. Kain, C. Corvalán, L. Lera, M. Galván, and R. Uauy, “Accelerated growth in early life and obesity in preschool chilean children," Obesity, vol. 17, no. 8, pp. 1603-1608, 2009. 


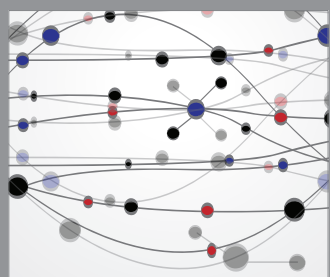

The Scientific World Journal
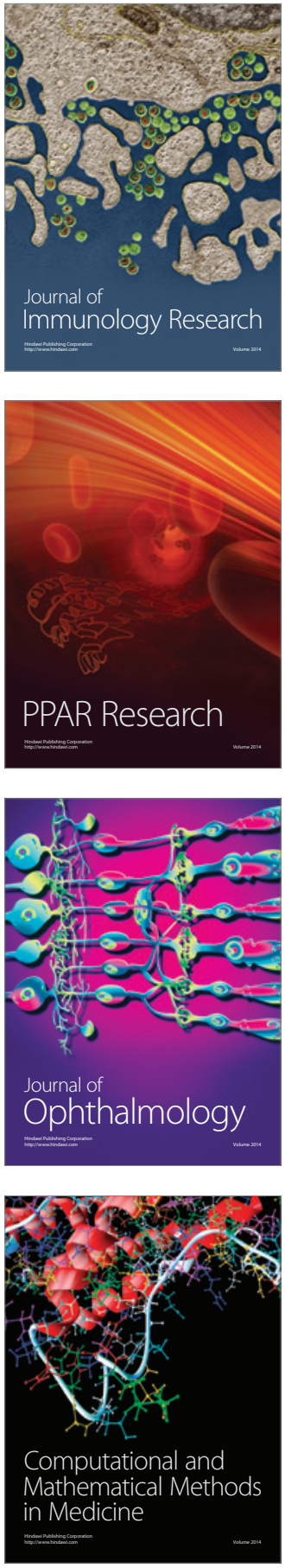

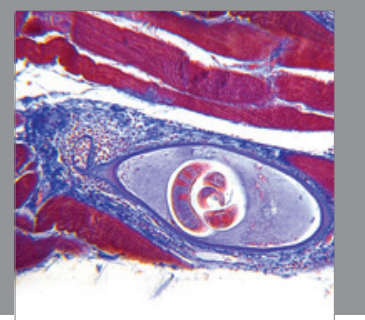

Gastroenterology

Research and Practice
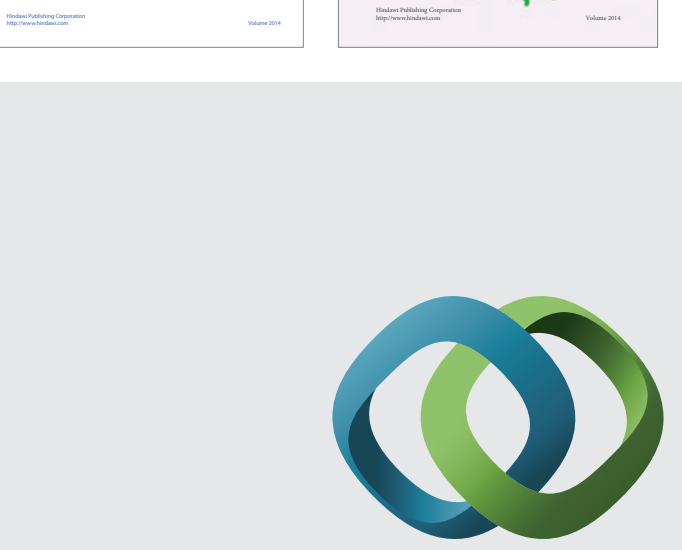

\section{Hindawi}

Submit your manuscripts at

http://www.hindawi.com
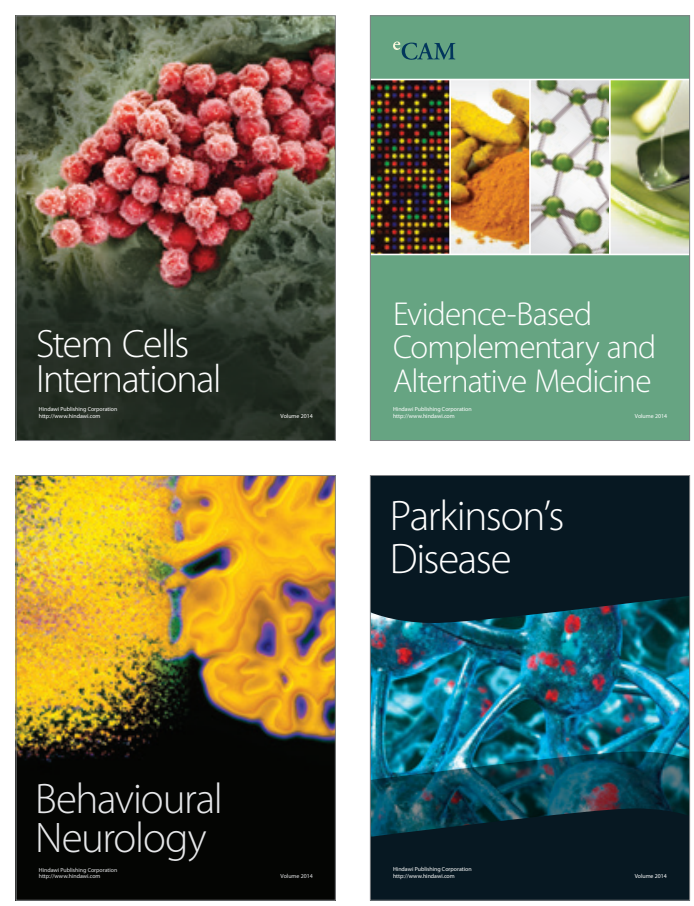

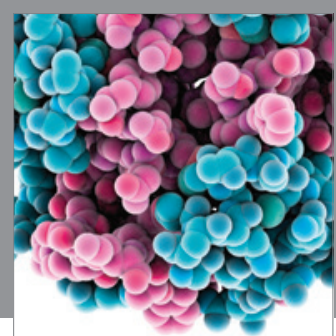

Journal of
Diabetes Research

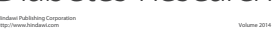

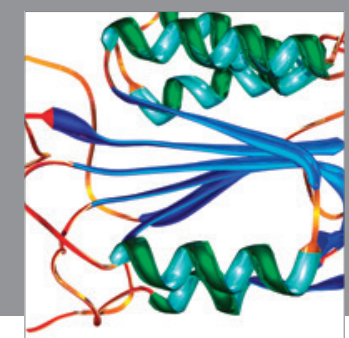

Disease Markers
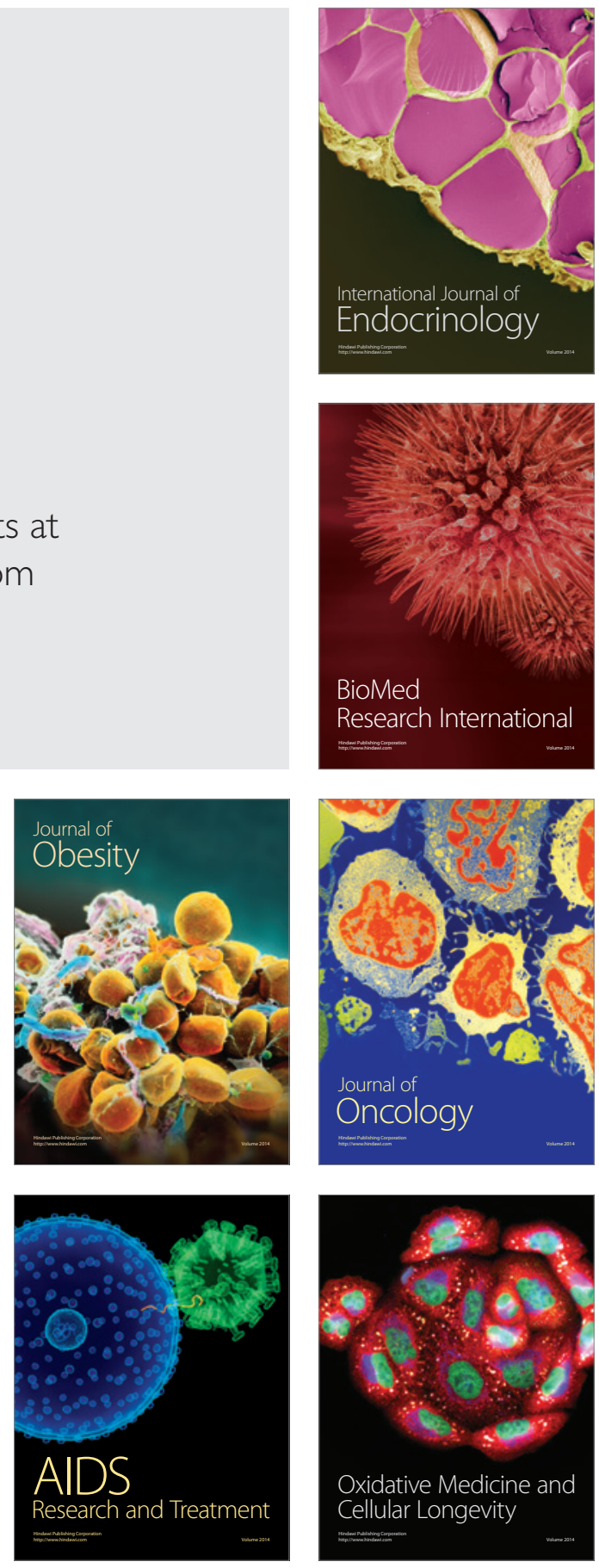